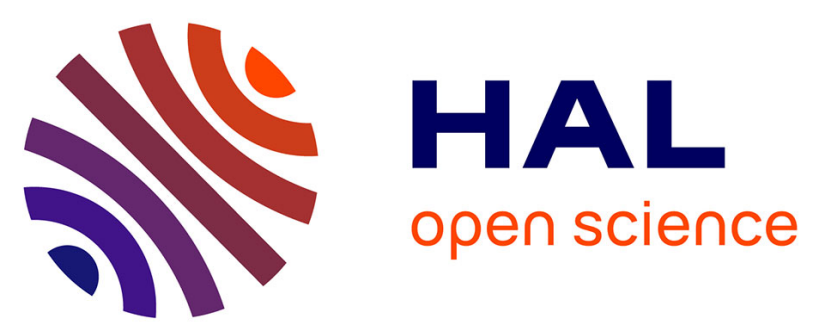

\title{
The effect of body mass index on overall and disease-free survival in node-positive breast cancer patients treated with docetaxel and doxorubicin-containing adjuvant chemotherapy: the experience of the BIG 02-98 trial
}

Evandro Azambuja, Worta Mccaskill-Stevens, Prudence Francis, Emmanuel Quinaux, John P. A. Crown, Malou Vicente, Rosa Giuliani, Bo Nordenskjöld, Jorge Gutiérez, Michael Andersson, et al.

\section{- To cite this version:}

Evandro Azambuja, Worta Mccaskill-Stevens, Prudence Francis, Emmanuel Quinaux, John P. A. Crown, et al.. The effect of body mass index on overall and disease-free survival in node-positive breast cancer patients treated with docetaxel and doxorubicin-containing adjuvant chemotherapy: the experience of the BIG 02-98 trial. Breast Cancer Research and Treatment, 2009, 119 (1), pp.145-153. 10.1007/s10549-009-0512-0 . hal-00535391

\author{
HAL Id: hal-00535391 \\ https://hal.science/hal-00535391
}

Submitted on 11 Nov 2010

HAL is a multi-disciplinary open access archive for the deposit and dissemination of scientific research documents, whether they are published or not. The documents may come from teaching and research institutions in France or abroad, or from public or private research centers.
L'archive ouverte pluridisciplinaire HAL, est destinée au dépôt et à la diffusion de documents scientifiques de niveau recherche, publiés ou non, émanant des établissements d'enseignement et de recherche français ou étrangers, des laboratoires publics ou privés. 


\title{
The effect of body mass index on overall and disease-free survival in node-positive breast cancer patients treated with docetaxel and doxorubicin-containing adjuvant chemotherapy: the experience of the BIG 02-98 trial
}

\author{
Evandro de Azambuja • Worta McCaskill-Stevens • Prudence Francis • \\ Emmanuel Quinaux · John P. A. Crown - Malou Vicente · Rosa Giuliani · \\ Bo Nordenskjöld · Jorge Gutiérez • Michael Andersson - Mireia Margeli Vila • \\ Raimund Jakesz · Jan Demol · Joanna Dewar · Armando Santoro · \\ Ana Lluch · Steven Olsen · Richard D. Gelber · Angelo Di Leo · \\ Martine Piccart-Gebhart
}

Received: 6 August 2009/Accepted: 8 August 2009/Published online: 3 September 2009

(C) Springer Science+Business Media, LLC. 2009

\begin{abstract}
Background: Obesity has been shown to be an indicator of poor prognosis for patients with primary breast cancer (BC) regardless of the use of adjuvant systemic therapy. Patients and methods: This is a retrospective analysis of 2,887 node-positive BC patients enrolled in the BIG 02-98 adjuvant study, a randomised phase III trial whose primary objective was to evaluate disease-free survival
\end{abstract}

On behalf of the BIG 02-98 Study Team.

Previous presentation: presented in part at the European Breast Cancer Conference (EBCC)-6, April 15-19, 2008, Berlin, Germany.

E. de Azambuja · M. Piccart-Gebhart ( $\square)$

Institut Jules Bordet and Université Libre de Bruxelles (U.L.B),

Boulevard de Waterloo, 125, 1000 Brussels, Belgium

e-mail: martine.piccart@bordet.be

W. McCaskill-Stevens

National Cancer Institute, National Institutes of Health,

Bethesda, MD, USA

P. Francis

Peter MacCallum Cancer Centre and St Vincent's Hospital, Australian New Zealand Breast Cancer Trials Group,

Melbourne, VIC, Australia

P. Francis

Australian New Zealand Breast Cancer Trials Group,

Newcastle, Australia

P. Francis

International Breast Cancer Study Group, Bern, Switzerland

E. Quinaux

International Drug Development Institute, Louvain-La-Neuve,

Belgium
(DFS) by adding docetaxel to doxorubicin-based chemotherapy. In the current analysis, the effect of body mass index (BMI) on DFS and overall survival (OS) was assessed. BMI was obtained before the first cycle of chemotherapy. Obesity was defined as a BMI $\geq 30 \mathrm{~kg} / \mathrm{m}^{2}$. Results: In total, 547 (19\%) patients were obese at baseline, while 2,340 (81\%) patients were non-obese. Estimated 5-year OS was $87.5 \%$ for non-obese and $82.9 \%$ for obese patients (HR 1.34; $P=0.013$ ). Estimated 5-years DFS was $75.9 \%$ for nonobese and $70.0 \%$ for obese patients (HR $1.20 ; P=0.041)$. In a multivariate model, obesity remained an independent

J. P. A. Crown

St. Vincent's Hospital, Dublin, Ireland

M. Vicente

Br.E.A.S.T. Data Centre, Brussels, Belgium

R. Giuliani

Medical Oncology Unit, S. Camillo-Forlanini Hospital, Rome, Italy

B. Nordenskjöld

Universitetssjukhuset, Oncology, Linköping, Sweden

J. Gutiérez

Clinica Las Condes, Las Condes, Santiago, Chile

M. Andersson

Department of Oncology, The Finsen Centre, Copenhagen

University Hospital, Rigshospitalet, Denmark

M. M. Vila

Hospital Germans Trias I Pujol, Badalona, Spain 
prognostic factor for OS and DFS. Conclusions: In this study, obesity was associated with poorer outcome in node-positive $\mathrm{BC}$ patients. Given the increasing prevalence of obesity worldwide, more research on improving the treatment of obese $\mathrm{BC}$ patients is needed.

Keywords Breast cancer - Obesity - BMI .

Adjuvant chemotherapy $\cdot$ Docetaxel $\cdot$ Node-positive

\section{Introduction}

It is estimated that the worldwide incidence of breast cancer in 2010 will be 1.45 million women [1]. In the United States alone, an estimated 182,460 women were to be diagnosed with breast cancer, and 40,480 women were to die from this disease in 2008 [2]. In the European Union, an estimated 319,900 women were diagnosed with breast cancer and 85,300 women died from this disease in 2006 [3]. There has been a dramatic increase in the prevalence of obesity throughout the developed and developing world over the past 20 years. Obesity prevalence varies from country to country, but overall an estimated 300 million people worldwide are obese [4]. In 2007, only one state in the USA (Colorado) had a prevalence of obesity $<20 \%$. Thirty states had a prevalence $\geq 25 \%$; three of these states (Alabama, Mississippi and Tennessee) had a prevalence of obesity $\geq 30 \%$ [5]. In general, more women than men are obese [6].

Body mass index (BMI), defined as the weight in kilograms divided by the square of the height in meters $\left(\mathrm{kg} / \mathrm{m}^{2}\right)$, is often categorized according to the recommendations of the World Health Organization (WHO): $<18.5$

\section{R. Jakesz}

University of Vienna, General Hospital, Vienna, Austria

J. Demol

Heilig Hart Ziekenhuis, Roeselare, Belgium

J. Dewar

Sir Charles Gairdner Hospital, Nedlands, Western Australia

A. Santoro

Istituto Clinico Humanitas, Rozzano, Italy

A. Lluch

Hospital Clinico Universitario, Valencia, Spain

S. Olsen

Sanofi-aventis, Paris, France

R. D. Gelber

Department of Biostatistics and Computational Biology,

Dana-Farber Cancer Institute, Boston, MA, USA

A. Di Leo

Sandro Pitigliani Medical Oncology Unit, Hospital of Prato,

Piazza dell'Ospedale, Prato, Italy (underweight), 18.5-24.99 (normal range), 25-29.99 (overweight), $\geq 30-34.99$ (obese) and $\geq 35$ (excess obesity) [7].

Several studies, including a meta-analyses, have shown that obesity is an adverse prognostic factor in breast cancer patients; however, results were not consistent across all studies since different patient populations (e.g. extent of disease, menopausal status, estrogen receptor status), treatments and BMI cut-offs have been included in these analyses [8-11]. Obesity has been associated with poor outcomes in pre- and postmenopausal patients, and this is not entirely explained by differences in tumor size or nodal status [12]. Notably, obese patients are more likely to receive a lower chemotherapy dose $(<85 \%$ of expected dose) for the first course compared with patients with normal or intermediate (overweight) BMI, and this reduction impacts negatively on the outcome, particularly in patients with estrogen receptor (ER)-negative tumors [13]. Also, obesity has been associated with an increased risk of contralateral breast cancer and second primary cancers in some studies [8, 14].

Anthracyclines and taxanes have been shown to improve the outcome when used as adjuvant treatment for nodepositive breast cancer patients and are widely used [15-17]. To further explore the relationship between obesity and outcome in patients with $\mathrm{BC}$, we performed a retrospective analysis of data from a prospective phase III trial including 2,887 women with node-positive breast cancer. The Breast International Group (BIG) 02-08 randomised trial tested the effect of incorporating docetaxel into anthracyclinebased adjuvant chemotherapy and compared sequential versus concurrent administration of doxorubicin and docetaxel. This trial showed that sequential administration of docetaxel appears to produce a better disease-free survival (DFS) than anthracycline-based chemotherapy in node-positive breast cancer patients [15]. We report here the results of an unplanned subgroup analysis comparing clinical outcomes in obese and non-obese patients enrolled in the BIG 02-98 trial.

\section{Materials and methods}

The methods of the BIG 02-98 trial have previously been reported [15]. Briefly, eligible patients were aged 1870 years with operable, adequately resected breast cancer and at least one positive axillary lymph node among a minimum of eight dissected lymph nodes. A normal left ventricular ejection fraction and adequate hematologic, liver and renal function were required. All patients gave written or witnessed informed consent prior to randomization. Institutional Ethics Committees approved the protocol at all participating sites. 
In total, 2,887 patients were randomly assigned to one of the following four chemotherapy arms: (1) four cycles of intravenous (i.v.) doxorubicin $75 \mathrm{mg} / \mathrm{m}^{2}$ every 3 weeks followed by three cycles of cyclophosphamide, methotrexate and 5-fluorouracil (CMF); (2) four cycles of i.v. doxorubicin $60 \mathrm{mg} / \mathrm{m}^{2}$ plus i.v. cyclophosphamide $600 \mathrm{mg} / \mathrm{m}^{2}$ every 3 weeks, followed by three cycles of CMF; (3) three cycles of i.v. doxorubicin $75 \mathrm{mg} / \mathrm{m}^{2}$ every 3 weeks, followed by three cycles of i.v. docetaxel $100 \mathrm{mg} / \mathrm{m}^{2}$ every 3 weeks, followed by three cycles of CMF; (4) four cycles of i.v. doxorubicin $50 \mathrm{mg} / \mathrm{m}^{2}$ plus i.v. docetaxel $75 \mathrm{mg} / \mathrm{m}^{2}$ every 3 weeks, followed by three cycles of CMF. CMF was given every 4 weeks as oral cyclophosphamide at $100 \mathrm{mg} / \mathrm{m}^{2}$ on days $1-14$ and i.v. methotrexate $40 \mathrm{mg} / \mathrm{m}^{2}$ plus i.v. 5-fluorouracil $600 \mathrm{mg} / \mathrm{m}^{2}$ on days 1 and 8 . The duration of each chemotherapy regimen was 24 weeks, except for the sequential docetaxel regimen ( $\operatorname{arm} 3$ ) which was 30 weeks.

After chemotherapy, tamoxifen $20 \mathrm{mg} /$ day for 5 years was prescribed for patients with ER- and/or progesterone receptor (PgR)-positive tumors. In 2004, a protocol amendment allowed for the use of aromatase inhibitors in postmenopausal women and the addition of ovarian suppression in premenopausal women. This trial was conducted before the approval of adjuvant trastuzumab therapy. Radiation was mandatory after breast-conserving surgery and administered after mastectomy according to institutional guidelines.

Chemotherapy doses were given according to baseline body surface area (BSA). Actual body weight was used for calculation of BSA, and ideal body weight was not utilized. BSA was recalculated if there was a $10 \%$ or greater decrease in body weight compared to baseline. After one obese patient died due to treatment-related toxicity, a protocol amendment in December 2000 limited the chemotherapy dose to a maximum BSA of $2.0 \mathrm{~m}^{2}$. At the time of this amendment, approximately $75 \%$ of total trial patients had been accrued. BMI was calculated, using height and weight at baseline, as the weight in kilograms divided by height in meters squared.

\section{Statistical considerations}

According to the World Health Organization, patients can be classified in 5 BMI subgroups: underweight $<18.5 \mathrm{~kg} /$ $\mathrm{m}^{2}$; normal 18.5-24.9 kg/m ${ }^{2}$; overweight $25.0-29.9 \mathrm{~kg} / \mathrm{m}^{2}$; obesity $30.0-34.9 \mathrm{~kg} / \mathrm{m}^{2}$; and excess obesity $\geq 35 \mathrm{~kg} / \mathrm{m}^{2}$. In our analyses, obesity was defined as a BMI $\geq 30 \mathrm{~kg} / \mathrm{m}^{2}$.

Stratified Cox proportional hazards regression model was used to assess adjusted effect of BMI on DFS and overall survival (OS) [18]. Models were stratified for hormone receptor status, age, menopausal status and number
Table 1 Patient and tumor characteristics

\begin{tabular}{|c|c|c|}
\hline & $\begin{array}{l}\text { Obese } \\
(n=547 ; 19 \%)\end{array}$ & $\begin{array}{l}\text { Non-obese } \\
(n=2,340 ; 81 \%)\end{array}$ \\
\hline Median age (range) & $52(29-69)$ & $48(27-70)$ \\
\hline$<50$ years & $205(37.5 \%)$ & $1,337(57.1 \%)$ \\
\hline \multirow[t]{2}{*}{$\geq 50$ years } & $342(62.5 \%)$ & $1,003(42.9 \%)$ \\
\hline & & $P<0.001$ \\
\hline \multicolumn{3}{|l|}{ Menopausal status } \\
\hline Premenopausal & $226(41.3 \%)$ & $1,326(56.7 \%)$ \\
\hline Postmenopausal & $297(54.3 \%)$ & $876(37.4 \%)$ \\
\hline \multirow[t]{2}{*}{ Other } & $24(4.4 \%)$ & $138(5.9 \%)$ \\
\hline & & $P<0.001$ \\
\hline \multicolumn{3}{|l|}{ pTumour size } \\
\hline$\leq 2 \mathrm{~cm}$ & $192(35.1 \%)$ & $951(40.6 \%)$ \\
\hline $2.1-5.0 \mathrm{~cm}$ & $315(57.6 \%)$ & $1,208(51.6 \%)$ \\
\hline$>5 \mathrm{~cm}$ & $39(7.1 \%)$ & $168(7.2 \%)$ \\
\hline \multirow[t]{2}{*}{ Unknown } & $1(0.2 \%)$ & $13(0.6 \%)$ \\
\hline & & $P=0.0527$ \\
\hline \multicolumn{3}{|l|}{ Positive lymphnodes } \\
\hline $1-3$ & $272(49.7 \%)$ & $1,295(55.3 \%)$ \\
\hline $4-10$ & $190(34.7 \%)$ & $759(32.4 \%)$ \\
\hline \multirow[t]{2}{*}{$>10$} & $85(15.5 \%)$ & $286(12.2 \%)$ \\
\hline & & $P=0.029$ \\
\hline \multicolumn{3}{|l|}{ Hormone receptor status } \\
\hline At least 1 positive & $404(73.9 \%)$ & $1,776(75.9 \%)$ \\
\hline \multirow[t]{2}{*}{ Negative } & $143(26.1 \%)$ & $564(24.1 \%)$ \\
\hline & & $P=0.32$ \\
\hline \multicolumn{3}{|l|}{ Surgery } \\
\hline Breast conservation & $217(39.7 \%)$ & $948(40.5 \%)$ \\
\hline \multirow[t]{2}{*}{ Mastectomy } & $297(54.3 \%)$ & $1,285(54.9 \%)$ \\
\hline & & $P=0.33$ \\
\hline \multicolumn{3}{|c|}{ Adjuvant endocrine therapy } \\
\hline \multirow[t]{2}{*}{ Yes } & $399(72.9 \%)$ & $1,726(73.8 \%)$ \\
\hline & & $P=0.70$ \\
\hline \multicolumn{3}{|l|}{ Previous disease } \\
\hline Cardiac & $182(33.2 \%)$ & $\begin{aligned} 272 & (11.6 \%) \\
\quad(P & <\mathbf{0 . 0 0 0 1})\end{aligned}$ \\
\hline Diabetes & $42(7.6 \%)$ & $\begin{array}{l}34(1.45 \%) \\
\quad(P<\mathbf{0 . 0 0 0 1})\end{array}$ \\
\hline \multicolumn{3}{|l|}{ BSA } \\
\hline Median & 1.9 & 1.7 \\
\hline \multirow[t]{2}{*}{ Range } & $1.6-2.3$ & $1.3-2.1$ \\
\hline & & $P<0.0001$ \\
\hline \multicolumn{3}{|l|}{ BMI } \\
\hline Median & 34.3 & 24.2 \\
\hline \multirow[t]{2}{*}{ Range } & $30.0-54.9$ & 15.9-29.9 \\
\hline & & $P<0.0001$ \\
\hline
\end{tabular}

Bold text indicates statistical significance

$B M I$ body mass index, BSA body surface area 
Table 2 Mean cumulative and relative doses of chemotherapy in obese and non-obese patients

Bold text indicates statistical significance

${ }^{\text {a }}$ Two thirds of patients were randomized to receive docetaxel

${ }^{\mathrm{b}}$ Missing patients is because some patients did not start treatment or have insufficient data. Data for each drug is reported separately and not as a regimen

${ }^{c}$ Mean cumulative dose of CMF was not calculated

\begin{tabular}{lll}
\hline & $\begin{array}{l}\text { Obese } \\
(n=547 ; 19 \%)\end{array}$ & $\begin{array}{l}\text { Non-obese } \\
(n=2,340 ; 81 \%)\end{array}$ \\
\hline Docetaxel $^{\text {a }}$ & 365 & 1,530 \\
${\text { Mean cumulative dose }\left(\mathrm{mg} / \mathrm{m}^{2}\right)}_{\text {Mean relative dose intensity }(\%)}$ & 283.7 & $287.2(P=0.43)$ \\
Doxorubicin & 95.0 & $96.0(P=0.72)$ \\
Mean cumulative dose $\left(\mathrm{mg} / \mathrm{m}^{2}\right)$ & $543^{\mathrm{b}}$ & $2,322^{\mathrm{b}}$ \\
& 228.4 & 227.6 \\
Mean relative dose intensity (\%) & & $P=0.64$ \\
& 97.7 & 96.9 \\
MMF $^{\mathrm{c}}$ & & $P=0.87$ \\
Mean relative dose intensity (\%) & $543^{\mathrm{b}}$ & $2,322^{\mathrm{b}}$ \\
& 92.8 & 91.9 \\
& & $\boldsymbol{P}=\mathbf{0 . 0 1}$ \\
\hline
\end{tabular}

Table 3 Five-year overall and disease-free survival in 2,887 nodepositive breast cancer patients according to BMI categories

\begin{tabular}{|c|c|c|c|c|}
\hline Subgroup & No. pts & 5-years (\%) & $\mathrm{HR}(95 \% \mathrm{CI})$ & $P$ value \\
\hline \multicolumn{5}{|l|}{ Overall survival } \\
\hline Non-obese ${ }^{a}$ & 2,340 & 87.5 & & \\
\hline Obese & 547 & 82.9 & $1.34(1.06-1.69)$ & 0.013 \\
\hline Underweight $^{\mathrm{b}}$ & 50 & 91.3 & $0.80(0.33-1.96)$ & 0.63 \\
\hline Normal & 1,315 & 89.3 & Reference & \\
\hline Overweight & 975 & 84.9 & $1.24(0.98-1.56)$ & 0.069 \\
\hline Obesity & 371 & 84.9 & $1.44(1.07-1.94)$ & 0.016 \\
\hline Excess obesity & 176 & 79.7 & $1.56(1.07-2.28)$ & 0.021 \\
\hline Subgroup & No. pts & 5-years (\%) & $\mathrm{HR}(95 \% \mathrm{CI})$ & $P$ value \\
\hline \multicolumn{5}{|l|}{ Disease-free survival } \\
\hline Non-obese $\mathrm{e}^{\mathrm{a}}$ & 2,340 & 75.9 & & \\
\hline Obese & 547 & 70.0 & $1.20(1.01-1.44)$ & 0.041 \\
\hline Underweight $^{\mathrm{b}}$ & 50 & 67.0 & $1.59(0.97-2.59)$ & 0.065 \\
\hline Normal & 1,315 & 78.0 & Reference & \\
\hline Overweight & 975 & 73.6 & $1.15(0.97-1.37)$ & 0.10 \\
\hline Obesity & 371 & 69.5 & $1.41(1.13-1.76)$ & 0.003 \\
\hline Excess obesity & 176 & 71.2 & $1.10(0.80-1.50)$ & 0.56 \\
\hline
\end{tabular}

Bold text indicates statistical significance

$C I$ confidence interval, $H R$ hazard ratios

a Using cut-off of $\geq 30 \mathrm{Kg} / \mathrm{m}^{2}$

${ }^{\mathrm{b}}$ Using WHO classification: underweight $<18.5 \mathrm{~kg} / \mathrm{m}^{2}$; normal $18.5-24.9 \mathrm{~kg} / \mathrm{m}^{2}$; overweight $25.0-29.9 \mathrm{~kg} / \mathrm{m}^{2}$; obesity $30.0-34.9 \mathrm{~kg} /$ $\mathrm{m}^{2}$ and excess obesity $\geq 35 \mathrm{~kg} / \mathrm{m}^{2}$

of positive lymph nodes. Multivariate models with hormone receptor status, age, menopausal status, tumor size and number of positive lymph nodes as covariates were fitted as sensitivity analyses.

BMI was used as a dichotomous variable in the model. Kaplan-Meier methods were used to estimate survival curves. Interaction tests between BMI and other patient characteristics were performed to determine whether the effect of BMI differed depending on the level of the variables. DFS was calculated from the date of randomization to the first date of a local, regional, or distant relapse; of the diagnosis of a second primary cancer, including contralateral invasive breast cancer; or of death from any cause. Stratified Log rank tests were used to compare time to death (when death was the first event), time to distant relapse and time to second primary cancer between obese and nonobese patients. Overall survival was calculated from the date of randomization to the date of death from any cause.

All reported $P$ values are two-sided, and $P<0.05$ was considered statistically significant. All statistical analyses were performed using SAS for Windows (release 9.1; SAS Institute, Cary, NC).

\section{Results}

Relationship between patient and tumor characteristics and BMI categories

In total, 2,887 patients were enrolled in the BIG 02-98 phase III trial from June 10, 1998 to June 26, 2001. The median follow-up at the time of this analysis was 62.5 months. Using the cut-off of $\geq 30 \mathrm{Kg} / \mathrm{m}^{2}, 547$ patients (19\%) were classified as obese, and 2,340 patients $(81 \%)$ were classified as non-obese at study entry. Patient and tumor characteristics are described in Table 1. Median age was 52 years (29-69) in obese and 48 years (27-70) in non-obese patients. Obese patients were more likely to be older ( $\geq 50$ years), postmenopausal, to have larger tumors $(2.1-5.0 \mathrm{~cm})$, and 4 or more positive lymph nodes compared with non-obese patients. Obese patients were more likely to have a history of cardiac disease and diabetes at study entry compared with non-obese patients $(P<0.001$ for both). 
There were no significant differences in mean cumulative dose (calculated as $\mathrm{mg} / \mathrm{m}^{2}$ ) and relative dose intensity for doxorubicin and docetaxel between obese and nonobese patients, although, obese patients were more likely to receive a slightly higher mean relative dose intensity of CMF (Table 2). Therefore, no undertreatment was observed in our obese patient population. During chemotherapy administration, 604 patients $(21.08 \%)$ had dose reductions with non-significant differences between obese and non-obese patients (20.3 versus $21.3 \%$, respectively; $P=0.6)$.

\section{Obesity and survival}

Obese patients had a worse outcome compared with nonobese patients in terms of overall survival and DFS (Table 3). Estimated 5-year overall survival was $82.9 \%$ for obese and $87.5 \%$ for non-obese patients [Hazard ratio (HR) 1.34; 95\% confidence interval (CI) 1.06-1.69; $P=0.0134$; unadjusted HR 1.48; $P=0.0007$ ] and estimated 5-year DFS was $70.0 \%$ for obese and $75.9 \%$ for non-obese patients (HR 1.20; 95\% CI 1.01-1.44; $P=0.041$; unadjusted HR 1.29; $P=0.005$ ) (Fig. 1a, b). When diabetes and history of cardiac disease were added to the model, obesity remained a significant prognostic factor $(P=0.03$ for DFS and $P=0.006$ for OS). These differences were also evident when the population was divided according to the 5 WHO BMI subgroups $(P=0.016$ for "obesity" versus normal for overall survival, and $P=0.003$ for "obesity" versus normal for DFS) (Table 3).

There were no significant differences between obese and non-obese patients in terms of time to death as first event, time to breast cancer relapse and time to second primary tumor.

In univariate analysis, among obese patients, those with $\geq 4$ positive lymph nodes $(P=0.012)$, or who were premenopausal $(P=0.01)$ or age $<50$ years at randomization (0.0011) had a significantly worse overall survival compared with non-obese patients (Fig. 2a, b). The detrimental effect of obesity on overall survival was greater for younger than for older women $(P$ interaction test $=0.041)$ (Fig. 2a). In a multivariate model with hormone receptor status, age, menopausal status, tumor size and number of positive lymph nodes as covariates, obesity remains an independent prognostic factor for overall survival (HR 1.36; $P=0.008$ ) and DFS (HR1.20; $P=0.04$ ) (Table 4).

In this study, we also performed subgroup analysis according to ER and PgR status (Fig. 2a, b). In this analysis, obese patients appear to have a worse outcome in patients with at least one hormone receptor negative. At the moment of this analysis, the results of HER2 status were not available but, in the future, such an analysis may provide additional insights into these results.

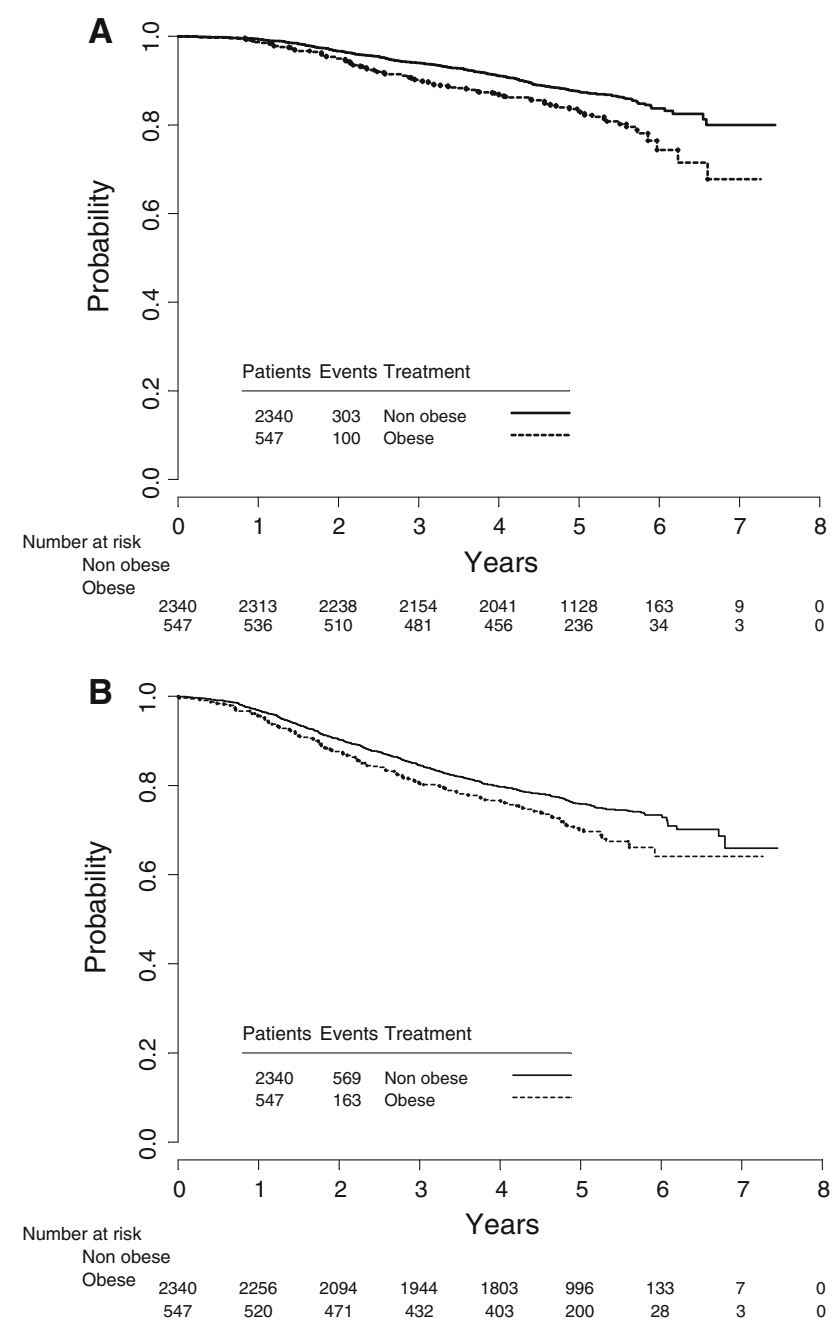

Fig. 1 a Kaplan-Meier estimates of overall survival by obesity at baseline for obese versus non-obese patients. b Kaplan-Meier estimates of disease-free survival by obesity at baseline for obese versus non-obese patients

Regarding Grade 3-4 adverse events, obese patients were more likely to have diarrhea, hyperglycemia, hypertension, infection and hospitalization due to an adverse event than non-obese patients (Table 5).

\section{Discussion}

In this retrospective analysis of a large, well-conducted, randomised phase III trial of adjuvant chemotherapy, obesity was associated with poorer outcome in terms of overall survival and DFS, remaining an independent prognostic factor in the multivariate model. A cohort of obese node-positive patients $(n=833)$ included in several International Breast Cancer Study Group trials had a worse 10-year overall survival, but no difference was seen in DFS [19]. 
Fig. 2 a Forest-plot estimates of overall survival for obese versus non-obese patients according to different subgroups. b Forest-plot estimates of disease-free survival for obese versus nonobese patients according to different subgroups. $C I$ confidence interval, $E R$ estrogen receptor, $H R$ hazard ratios, $L N$ lymphnode, $\mathrm{Neg}$ negative, $\mathrm{PgR}$ progesterone receptor, \# number and + positive
A

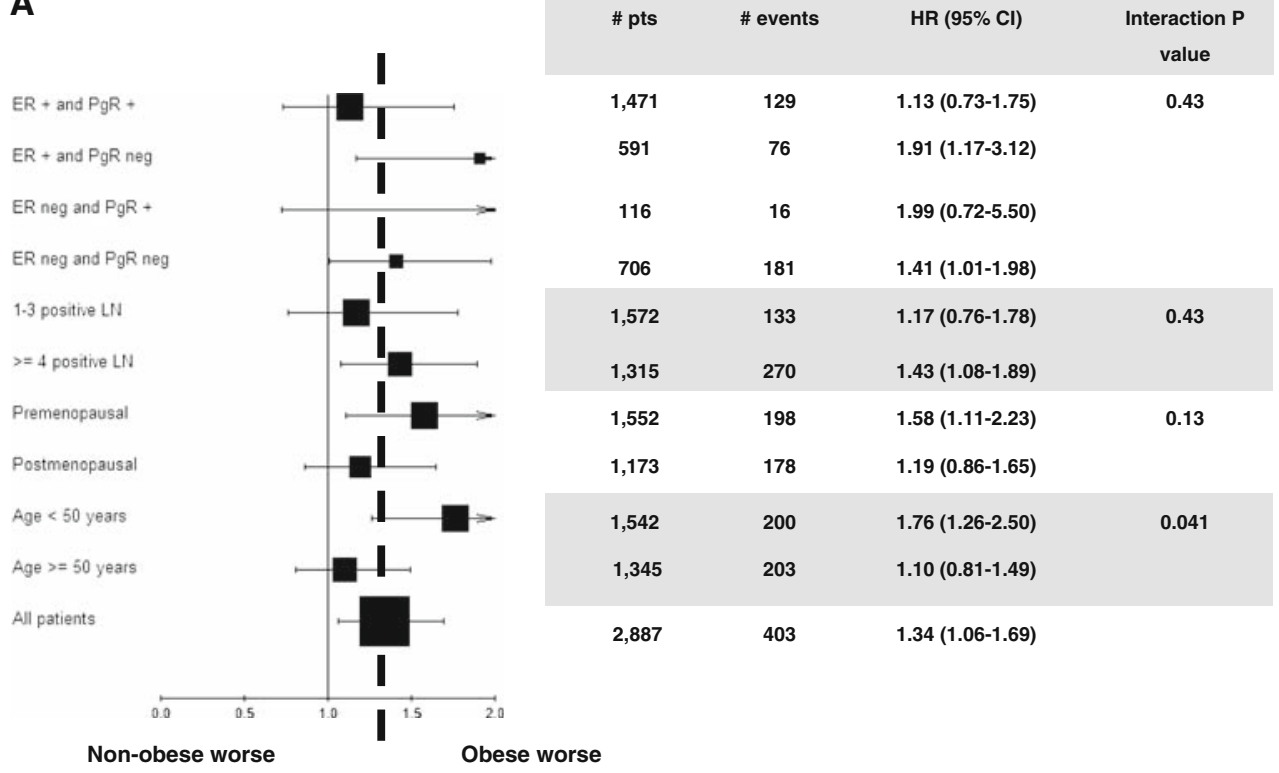

B

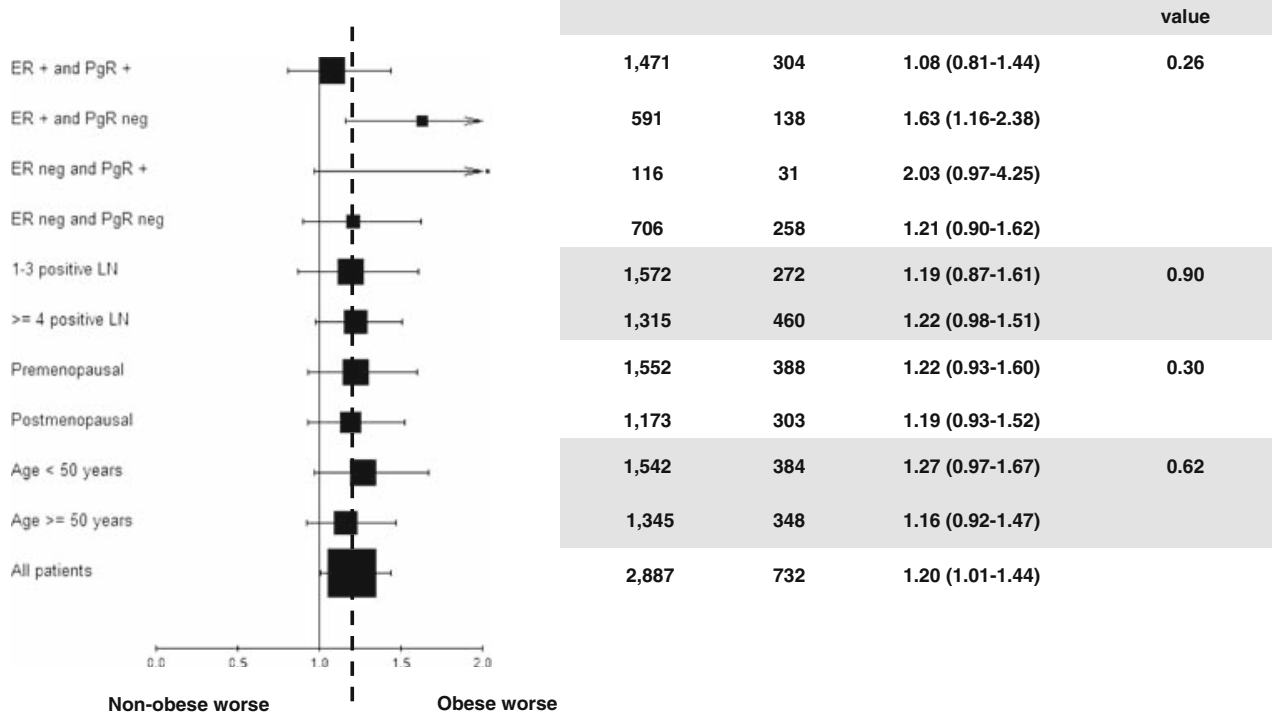

Other studies have shown that obese patients are more likely to be undertreated because of chemotherapy dose adjustments. However, in our study, no significantly lower treatment dose or intensity had been given to obese patients. In a recent review of 44 trials, of 22 protocols initiated prior to December 1984, 21 (95\%) either did not directly address dose determinations in obese patients $(n=9)$ or specified dose reduction $(n=12)$ in obese patients. By contrast, of 22 protocols initiated after December 1984, 10 (45\%) specified full weight-based dosing, 7 (32\%) specified dose limits and 5 (23\%) provided no specific information on chemotherapy dosing in obese patients $(P=0.004)$ [20]. Importantly, underdosing chemotherapy may contribute to the poorer survival rates in patients with breast cancer, particularly in those with ERnegative tumors [13].

A retrospective analysis of the relationship between BMI and pathologic response (pCR) in 1,169 patients receiving neoadjuvant chemotherapy showed that obese patients were more likely to have ER-negative tumors $(P=0.01)$, stage III tumors $(P<0.01)$ and worse OS $(P=0.006)$. In the multivariate model, there was no significant difference in pathologic complete response (pCR) rates to neoadjuvant chemotherapy for obese compared with normal/underweight patients. However, when overweight and obese groups were combined and compared with normal/underweight groups, there was a significant association, with higher BMI associated with lower pCR 
Table 4 Events used for disease-free and overall survival calculations

\begin{tabular}{|c|c|c|}
\hline & $\begin{array}{l}\text { Obese } \\
(n=547 ; 19 \%)\end{array}$ & $\begin{array}{l}\text { Non-obese } \\
(n=2,340 ; 81 \%)\end{array}$ \\
\hline Death (all) & $100(18.3 \%)$ & $303(12.3 \%) P=0.013 * *$ \\
\hline Breast cancer & $91(91.0 \%)$ & $277(91.4 \%)$ \\
\hline Other & $9(9 \%)$ & $26(8.6 \%)$ \\
\hline Death $(\text { first event })^{\mathrm{a}}$ & 6 & $14 P=0.30^{* *}$ \\
\hline Breast cancer & $1(16.7 \%)$ & $5(35.7 \%)$ \\
\hline Other & $4(66.7 \%)$ & $4(28.6 \%)$ \\
\hline $\begin{array}{l}\text { Septic from study } \\
\text { therapy }\end{array}$ & $1(16.7 \%)$ & $3(21.4 \%)$ \\
\hline Missing or unknown & 0 & $2(14.3 \%)$ \\
\hline $\begin{array}{l}\text { Breast cancer } \\
\text { relapse }^{*, \mathrm{~b}}\end{array}$ & 139 & $502 P=0.078^{* *}$ \\
\hline Local & $22(15.8 \%)$ & $95(18.9 \%)$ \\
\hline Regional & $7(5 \%)$ & $34(6.8 \%)$ \\
\hline Distant & $120(86.3 \%)$ & $414(82.5 \%)$ \\
\hline $\begin{array}{l}\text { Second primary } \\
\text { tumor }^{\mathrm{c}}\end{array}$ & 17 & $53 P=0.48 * *$ \\
\hline Endometrium & $2(11.8 \%)$ & $5(9.4 \%)$ \\
\hline Ovarian & $2(11.8 \%)$ & $2(3.8 \%)$ \\
\hline Breast & $5(29.4 \%)$ & $15(28.3 \%)$ \\
\hline Other & $8(47 \%)$ & $31(58.5 \%)$ \\
\hline
\end{tabular}

* Some patients may have more than one type of relapse

** Adjusted Log rank test comparing the time to event

${ }^{\text {a }}$ Obese $(1.09 \%)$ and non-obese $(0.6 \%)$

b Obese $(25.4 \%)$ and non-obese $(21.4 \%)$

c Obese $(3.1 \%)$ and non-obese $(2.2 \%)$

rates [21]. Unfortunately, chemotherapy-dosing patterns (dose administered and/or dose reductions) were not available in this study and reduction in dosing because of obesity may influence pCR and survival. Therefore, obesity may be linked not only to prognosis but also to prediction of response to neo-adjuvant chemotherapy.

In our study, worse overall survival was observed in obese patients with $\geq 4$ lymph nodes, premenopausal or patients aged $\leq 50$ years; however, interaction test was significant for age only (Fig. 2a). Our finding that BMI has a greater effect on prognosis in younger women and less effect on older or postmenopausal patients is consistent with the results of other studies [22, 23]. A trend toward a larger impact of obesity on worsening outcome was observed for patients with at least one hormone receptor negative, similar to the results of one other study [24].

The exact mechanism responsible for the effect of obesity on breast cancer outcomes remains unclear, but it is known that the obesity has effects on a number of hormones including estrogen and growth factors potentially
Table 5 Incidence of grade 3-4 adverse events in the safety population

\begin{tabular}{lcl}
\hline & $\begin{array}{l}\text { Obese } \\
(n=543 ; 19 \%)\end{array}$ & $\begin{array}{l}\text { Non-obese } \\
(n=2,322 ; 81 \%)\end{array}$ \\
\hline Allergy & 1.5 & 0.7 \\
Anemia & 1.8 & 2.6 \\
Any cardiac event & 0.7 & 0.6 \\
Diarrhea & $\mathbf{4 . 4}$ & $\mathbf{2 . 2}$ \\
Febrile neutropenia & 8.7 & 7.5 \\
Hyperglycemia & $\mathbf{0 . 7}$ & $\mathbf{0 . 1}^{* *}$ \\
Hypertension & $\mathbf{0 . 7}$ & $\mathbf{0 . 1} * * *$ \\
Infection & $\mathbf{8 . 8}$ & $\mathbf{4 . 7}^{\mathfrak{f}}$ \\
Myalgia & 1.5 & 1.2 \\
Nausea & 7.0 & 5.3 \\
Neurosensory & 0.4 & 0.2 \\
Pulmonary & 2.0 & 0.3 \\
Skin & 1.7 & 0.8 \\
Stomatitis & 5.5 & 4.9 \\
Thrombocytopenia & 2.8 & 2.2 \\
Vomiting & 5.9 & 4.8 \\
Hospitalization due to AE & $\mathbf{2 2 . 9}$ & $\mathbf{1 6 . 8}$ \\
Toxic death & 0.2 & 0.1 \\
\hline
\end{tabular}

Bold text indicates statistical significance. Values are given in percentage

* $P=0.027$

** $P=0.014$

$* * * P=0.028$

£ $P=0.002$

£f $P=0.0009$

linked to breast cancer. Also, the obesity-related consequences include altered concentrations of circulating adipocytokines and development of the insulin resistance including hyperinsulinemia and impaired glucose metabolism [25]. Obesity has been associated with an increased risk of developing breast cancer particularly in postmenopausal patients with ER-positive and PgR-positive tumors (82\% higher risk; 95\% CI 55-114\%) [26]. We found a worse outcome in subgroup analysis in those patients presenting ER-positive and PgR-negative tumors or both ER- and PgR-negative tumors (Fig. 2a, b). Although subgroup analyses may be informative, they are often confounded by the increased likelihood of false positive and/or negative results; therefore, they should always be interpreted with caution. Conversely, for women with lymph node-negative, ER-positive breast cancer included in the NSABP B14 trial, obesity was not associated with increase in recurrence risk or a change in tamoxifen efficacy, though there was an increased risk of contralateral breast cancer and overall mortality [27]. 
Obesity has also been studied in other solid tumors such as colon cancer. Notably, neither BMI nor weight changes (loss or gain during the time period between ongoing adjuvant chemotherapy and 6 months after its completion) were associated with a significantly increased risk of cancer recurrence and death in patients with colon cancer enrolled on a randomised phase III trial of adjuvant chemotherapy [28], which is in contrast with results of other studies demonstrating that obesity may be associated with these outcomes [29-31].

Some potential limitations for our study should be considered, and they include a lack of data collection on body habitus such as waist-hip ratio or waist circumference; also an analysis of changes in weight at the end of adjuvant chemotherapy or during follow-up was not performed; and the reporting of unplanned subgroup analysis. Nevertheless, our study has several strengths such as (a) the large sample size included in the analysis (nearly 3,000 patients); (b) the detailed information on previous diseases and the precise information on weight and height prior to chemotherapy and (c) homogenous treatment (adjuvant chemotherapy per protocol) given to patients rather than several regimens widely prescribed.

In spite of such limitations, this study strongly supports the negative effect of obesity in women with node-positive breast cancer treated with adjuvant chemotherapy within the framework of a large randomised trial. Given the increasing prevalence of obesity worldwide, more research on improving the treatment of obese breast cancer patients is needed.

Acknowledgments We thank the patients, physicians, nurses and data managers who participated in BIG 02-98 and the staff at the central offices of the cooperative groups. The following cooperative groups participated: Breast European Adjuvant Studies Team, International Breast Cancer Study Group (including Australian New Zealand Breast Cancer Trials Group), Irish Clinical Oncology Research Group, Grupo Español de Investigacion en Cancer de Mama, Danish Breast Cancer Cooperative Group, Swedish Breast Cancer Group, Austrian Breast and Colorectal Cancer Study Group and Grupo Oncologico Cooperative Chileno De Investigacion. The BIG 02-98 trial was supported by the National Health and Medical Research Council (project grants 100925 and 351164 to Australian New Zealand Breast Cancer Trials Group).

\section{References}

1. Ferlay J, Bray F, Pisani P, Parkin DM (2001) Globocan 2000. Cancer incidence, mortality and prevalence worldwide. Version 1.0. IARC CancerBase No. 5. IARCPress, Lyon

2. Cancer Facts \& Figs 2008 (2008) Graphs and figures. (In Edition 2008)

3. Ferlay J, Autier P, Boniol M et al (2007) Estimates of the cancer incidence and mortality in Europe in 2006. Ann Oncol 18:581-592

4. World Health Organization (2008) Controlling the global obesity epidemic (In Edition 2008)

5. U.S. Obesity Trends 1985-2007 (2008) (In Edition 2008)
6. Caterson ID, Gill TP (2002) Obesity: epidemiology and possible prevention. Best Pract Res Clin Endocrinol Metab 16:595-610

7. World Health Organization (2008) Global database on body mass index (In Edition 2008)

8. Dignam JJ, Wieand K, Johnson KA et al (2006) Effects of obesity and race on prognosis in lymph node-negative, estrogen receptornegative breast cancer. Breast Cancer Res Treat 97:245-254

9. Vitolins MZ, Kimmick GG, Case LD (2008). BMI influences prognosis following surgery and adjuvant chemotherapy for lymph node positive breast cancer. Breast J 14(4):357-365

10. Ryu SY, Kim CB, Nam CM et al (2001) Is body mass index the prognostic factor in breast cancer?: a meta-analysis. J Korean Med Sci 16:610-614

11. Chlebowski RT, Aiello E, McTiernan A (2002) Weight loss in breast cancer patient management. J Clin Oncol 20:1128-1143

12. Loi S, Milne RL, Friedlander ML et al (2005) Obesity and outcomes in premenopausal and postmenopausal breast cancer. Cancer Epidemiol Biomarkers Prev 14:1686-1691

13. Colleoni M, Li S, Gelber RD et al (2005) Relation between chemotherapy dose, oestrogen receptor expression, and body-mass index. Lancet 366:1108-1110

14. Majed B, Moreau T, Senouci K et al (2008) Is obesity an independent prognosis factor in woman breast cancer? Breast Cancer Res Treat 111:329-342

15. Francis P, Crown J, Di Leo A et al (2008) Adjuvant chemotherapy with sequential or concurrent anthracycline and docetaxel: Breast International Group 02-98 randomized trial. J Natl Cancer Inst 100: 121-133

16. Roche H, Fumoleau P, Spielmann M et al (2006) Sequential adjuvant epirubicin-based and docetaxel chemotherapy for nodepositive breast cancer patients: the FNCLCC PACS 01 Trial. J Clin Oncol 24:5664-5671

17. Martin M, Pienkowski T, Mackey J et al (2005) Adjuvant docetaxel for node-positive breast cancer. N Engl J Med 352:2302-2313

18. Cox DR (1972) Regression models and life-tables (with discussion). J Royal Stat Sc B 34:187-220

19. Berclaz G, Li S, Price KN et al (2004) Body mass index as a prognostic feature in operable breast cancer: the International Breast Cancer Study Group experience. Ann Oncol 15:875-884

20. Greenman CG, Jagielski CH, Griggs JJ (2008) Breast cancer adjuvant chemotherapy dosing in obese patients: dissemination of information from clinical trials to clinical practice. Cancer 112:2159-2165

21. Litton JK, Gonzalez-Angulo AM, Warneke CL et al (2008) Relationship between obesity and pathologic response to neoadjuvant chemotherapy among women with operable breast cancer. J Clin Oncol 26:4072-4077

22. Lees AW, Jenkins HJ, May CL et al (1989) Risk factors and 10-year breast cancer survival in northern Alberta. Breast Cancer Res Treat 13:143-151

23. Hebert JR, Hurley TG, Ma Y (1998) The effect of dietary exposures on recurrence and mortality in early stage breast cancer. Breast Cancer Res Treat 51:17-28

24. Maehle BO, Tretli S (1996) Pre-morbid body-mass-index in breast cancer: reversed effect on survival in hormone receptor negative patients. Breast Cancer Res Treat 41:123-130

25. Cust AE, Stocks T, Lukanova A et al (2009) The influence of overweight and insulin resistance on breast cancer risk and tumour stage at diagnosis: a prospective study. Breast Cancer Res Treat 113:567-576

26. Suzuki R, Orsini N, Saji S et al (2009) Body weight and incidence of breast cancer defined by estrogen and progesterone receptor statusA meta-analysis. Int J Cancer 124:698-712

27. Dignam JJ, Wieand K, Johnson KA et al (2003) Obesity, tamoxifen use, and outcomes in women with estrogen receptor-positive earlystage breast cancer. J Natl Cancer Inst 95:1467-1476 
28. Meyerhardt JA, Niedzwiecki D, Hollis D et al (2008) Impact of body mass index and weight change after treatment on cancer recurrence and survival in patients with stage III colon cancer: findings from Cancer and Leukemia Group B 89803. J Clin Oncol 26:4109-4115

29. Meyerhardt JA, Catalano PJ, Haller DG et al (2003) Influence of body mass index on outcomes and treatment-related toxicity in patients with colon carcinoma. Cancer 98:484-495
30. Dignam JJ, Polite BN, Yothers G et al (2006) Body mass index and outcomes in patients who receive adjuvant chemotherapy for colon cancer. J Natl Cancer Inst 98:1647-1654

31. Haydon AM, Macinnis RJ, English DR, Giles GG (2006) Effect of physical activity and body size on survival after diagnosis with colorectal cancer. Gut 55:62-67 